\title{
The crisis and regional employment in Europe: what role for sheltered economies?
}

\section{Ugo Fratesi ${ }^{\mathrm{a}}$ and Andrés Rodríguez-Pose ${ }^{\mathrm{b}}$}

${ }^{a}$ Department ABC, Politecnico di Milano

${ }^{\mathrm{b}}$ Department of Geography and Environment, London School of Economics

\section{Corresponding author:}

Andrés Rodríguez-Pose

Professor of Economic Geography

Department of Geography and Environment

London School of Economics

Houghton St

London WC2A 2AE

UK

e-mail: a.rodriguez-pose@1se.ac.uk

\section{Ugo Fratesi}

Associate professor of regional economics

Politecnico di Milano

Department ABC

Piazza Leonardo da Vinci, 32

Edificio 5

I-20133 Milano

Italy

E-mail: ugo.fratesi@polimi.it 


\title{
The crisis and regional employment in Europe: what role for
} sheltered economies?

\begin{abstract}
This paper examines how the evolution of employment trends in the regions of Europe since the outbreak of the crisis may have been shaped by the emergence of sheltered economies in certain regions of Europe in the pre-crisis period. The paper uses descriptive and econometric analysis to determine the relationship between the level of protection from the market of regional economies in the years of economic boom between 1995 and 2007 and employment trends in the first four years of the crisis (2008-2012). The analysis covers 272 NUTS2-level regions in 27 EU countries. The results of the analysis show that regions which had developed more sheltered economies during the boom years have not weathered the employment shock associated with the crisis well, while precrisis dynamism in employment generation has been connected to lower post-crisis employment destruction. The only exception are the most highly sheltered economies in the pre-crisis period, which have endured a lower level of job destruction than any other type of region. The question is whether this early resistance to job destruction can be maintained once the recovery starts.
\end{abstract}

JEL Codes: R11, R58

Keywords: economic crisis, employment, sheltered economies, regions, Europe. 


\section{Introduction}

This paper looks at the evolution of employment trends in the regions of Europe since the outbreak of the Great Recession in 2008. It aims to assess the extent to which the emergence of 'protected' or 'sheltered' economies - that is, economies that are "more impervious to changes in the business cycle" (Rodríguez-Pose and Fratesi, 2007: 624) - in certain regions of Europe in the years prior to the crisis is linked to the performance of these regions in terms of employment generation once the crisis set in. The focus is on how regional trends in employment destruction/generation during the early stages of the crisis (between 2008 and 2012) have been shaped by the formation of sheltered or, conversely, more open economies in the boom years between 1995 and 2007. We posit that the economic history of a given European region may determine the extent to which it has been capable of adapting and reacting to the conditions generated by crisis. Regions that have traditionally been more open to trade with the rest of the world are likely to react differently from regions which have been mostly protected from interaction. These 'protected' or 'sheltered' regions are "more protected from the risk of downturn in the cycle, but the structure of a sheltered economy will, in general, also be less capable of taking advantage of high growth periods" (Rodríguez-Pose and Fratesi, 2007: 624). More sheltered regions behave in a more a-cyclical way: the grow less in periods of economic boom, but also suffer less in periods of decline. Such a-cyclicity could in theory set up the conditions to better weather economic downturns, as the Great Recession which has affected Europe since 2008. However, as indicated in the above definition, 'sheltered' economies will also over time have developed a lack of capacity to respond to sudden changes in the business cycle. This may have important implications for employment as, on the one hand, the presence of sheltered sectors would protect them from massive immediate layoffs at the beginning of the downturn, but, on the other, their very lack of responsiveness may limit their capacity to fend off rising unemployment in a prolonged crisis. The definition of 'sheltered' or 'protected' economies 
used in the paper is not structural - i.e. looking at the sectoral specialization of regions - but factual, classifying regions as sheltered or open depending on their behaviour relative to the national average employment generation performance during the different phases of the economic cycle.

The choice of employment instead of GDP growth or productivity is related to the fact that variations in employment levels reflect better the social - and not necessarily the economic impact of the crisis than alternative variables. It has in fact been stressed that the crisis has destroyed jobs but the recovery, especially in many parts of the European periphery and even in the US, has often been jobless or delivered less jobs than expected (The Economist, 2012). This not to deny the importance of creating value added and increasing productivity, but the growth in employment can impact on the welfare of ordinary citizens more than the creation of value added, thus having a greater social impact. We also consider employment to be more significant than unemployment for the purpose of this analysis, as the latter is affected by not only the number of jobs available, but also by the participation of people in the labour market. A deep structural economic crisis such as the one Europe has been experiencing can strongly discourage the participation in the labour market of those who believe they do not have hope of finding work. A reduction of the active population automatically reduces the unemployment rate for purely statistical reasons. Using employment rates also has a practical advantage relative to using GDP: the statistical data for employment at the regional level in Europe are available with a smaller time lag than for GDP or value added. For this reason the time series data of employment is longer and allows to analyse a longer period of the crisis. The analysis covers changes in employment in 252 regions in 27 EU countries for the period between 1995-2007 and 2008-2012, respectively. 
The rest of the paper is structured as follows. In section 2 we briefly present a number of facts about how the 2008 Great Recession has affected regions in Europe. Section 3 discusses the territorially specific factors that may affect the different sensitivity of European regions to the crisis. Section 4 and 5 focus on the evolution of employment at the regional level during the crisis and assesses the presence of sheltered economies in the European Union. Section 6 presents the empirical analysis in order to verify, by means of multivariate regressions, whether protection from the economic cycle has any particular link to economic resilience, proxied by lower employment destruction since the outbreak of the crisis. Section 7 establishes the conclusions and some preliminary policy implications.

\section{Regions and the 2008 Great Recession}

The Great Recession that started in 2008 has hit Europe harder than any other crisis in the postWorld War II period. A crisis that had its roots in finance immediately spread across the whole of Europe, affecting some countries and regions more than others. The consequences of the crisis were quickly felt. By mid-2009 GDP per head in the European Union (EU) had already decreased by 5\% relative to its peak in the fourth quarter of 2007 and unemployment shot up from 7 to $11 \%$ between 2007 and 2013. The crisis also had serious effects on public finance. Europe as a whole experienced a significant rise in government deficits and in its debt to GDP ratio.

The effects of the crisis have been felt well beyond the economic dimension, generating important social and political consequences. On the social dimension, there has been a significant rise in longterm unemployment and social exclusion, phenomena which have been tied to an increase in poverty. The crisis has also triggered a renewal of European migration, with many young 
unemployed and often highly qualified individuals from southern Europe looking for jobs in the more dynamic markets of central and northern Europe, which have had a better performance in terms of employment and productivity than the southern rim of Europe (Fingleton et al. 2015). From a political perspective, the crisis has been associated with a rise of radical, anti-system, and as/or anti-European parties.

The impact of the crisis has been far from homogeneous across Europe. While Poland has been mostly spared by the downturn - the country did not experience a single quarter of decline in GDP - and employment in Germany has continued to grow throughout the crisis, many countries, especially in the southern - Cyprus, Greece, Italy, Portugal, and Spain - and eastern peripheries Bulgaria and Latvia - of the European Union have been particularly hard hit (Fingleton et al., 2015). In terms of GDP, Germany's GDP returned to its pre-crisis levels already in 2011. By contrast, a large number of countries are still below pre-crisis levels of GDP. In particular, Greece, Ireland, Italy, Portugal, and Spain, put together, have witnessed their GDP decline by $10 \%$ relative to 2007. Greece has been particularly hard-hit. Its GDP has shrunk by more than one quarter. In terms of employment, a huge gulf separates Greece (26\% unemployment in 2015) and Spain (23\%) from the rest of the European Union and especially from Germany and Austria where unemployment rates are below 5\%. Long-term unemployment is also much higher in Greece and Spain than elsewhere in the EU. And the panorama is by no means better when considering debt and public deficits. Public debt in Greece exceeds $175 \%$ of GDP and is above hundred percent in Belgium, Cyprus, Ireland, Italy, and Portugal. If household and non-financial corporate debts are considered, the total amount of debt in Ireland is close to $450 \%$ of GDP. Countries like Greece, Spain, Ireland, Portugal, Cyprus, and the UK have also incurred in huge public deficits. 
The gap between the core and the peripheries of Europe does, however, not hide the existence of significant within-country differences. Central Portugal, southern Spain, southern Italy, central Greece, the former East Germany, southern Romania, eastern Poland, northern England and Scotland have been particularly hard-hit by the crisis in terms of employment destruction, while the north of Italy, Bucharest, Madrid and most of northern Spain, South East England, southern Germany, or the three Nordic capitals performed relatively well relative to their respective countries.

\section{The theoretical determinants of sensitivity to crises}

\subsection{Adaptability to a crisis}

What determines these within-country differences in employment performance, especially at a time when most indicators are conducive to a significant destruction of employment? The reasons behind the differentiated spatial impact of the crisis are manifold. Regions where firms were more indebted have tended to suffer more from the crisis, as the supply of credit is not homogenous at national level (see, for example, Bank of Italy, 2013). Efforts at European level to maintain a strong Euro during the initial stages of the downturn also adversely affected regions whose economies are more dependent on exports, especially those regions specialised in products for which price is an important determinant of international competitiveness, such as the Italian industrial districts. These regions have been more adversely affected by a strong Euro than German car manufacturing regions, which are more reliant on high-tech, premium goods. 
Regional specialisation has also played a decisive part in how regions across Europe have weathered the crisis. Not all sectors have had suffered equally. Sudden variations of demand impact sectors differently and, hence, affect regions depending on their type and level of specialisation. Sectoral specialisation determined to a large extent whether regions where 'lucky' or 'unlucky'. The pharmaceutical industry, for example, was one of the 'lucky' ones. It sailed through the early stages of the downturn. The sector increased its revenues by $6.52 \%$ in the EU-27 in the period between 2008 and 2011, helping regions with a strong specialisation in pharmaceuticals, such as southern Germany or the South East of England, to perform rather well in those early stages of the crisis. By contrast, other sectors were strongly shaken by the downturn. Construction was possibly the most affected sector. During the same period its revenues contracted by $11.95 \%$, strongly upsetting the economies of many regions that were dependent on housebuilding. Spanish coastal areas, which had thrived during the economic boom years thanks to the construction and sale of second homes, are a clear example of the construction-led bust. Textiles has been another sector in rapid decline. It witnessed a reduction of $7.45 \%$ of its revenues in the initial period of the crisis, leading to redundancies in many regions of southern and Eastern Europe. The crisis also altered consumption patterns. Households were forced to reduce the consumption of non-essential goods in favour of essential ones.

As influential as the economic structure of a region has been its capacity to adapt and to find solutions to sudden changes in the economic conditions - in other words, its resilience (Pike et al., 2010; Martin, 2012). Although different authors use different definitions of resilience, Martin and Sunley, 2015: 13), in what is quickly becoming the most accepted definition of regional economic resilience, define it as:

"the capacity of a regional or local economy to withstand or recover from market, competitive and environmental shocks to its developmental growth path, 
if necessary by undergoing adaptive changes to its economic structures and its social and institutional arrangements, so as to maintain or restore its previous developmental path, or transit to a new sustainable path characterized by a fuller and more productive use of its physical, human and environmental resources" Martin and Sunley: 2015: 13).

Three types of resilience have been identified (Martin, 2012; Martin and Sunley, 2015): an 'engineering resilience', defined as the ability of a system to return to its stable state of equilibrium after a shock; an 'ecological resilience', defined as the scale of shock a system is able to absorb before it is de-stabilized and transferred to another state or stable configuration; an 'adaptive resilience', understood as the ability of a system to reorganize its forms or functions anticipating or reacting to destabilising shocks. Engineering resilience is associated to the concept of adaptation, that is the restoration in the short-term of "the renewal of a pre-conceived and previously successful development path" (Pike et al., 2010: 62; see also Grabher and Stark, 1997), while ecological and adaptive resilience are connected to the idea of adaptability, implying leaving "a path that may have proven successful in the past in favour of a new, related or alternative trajectory" (Pike et al., 2010: $62)$.

Such adaptation and adaptability requires flexibility, creativity, and innovation in equal measure. Flexibility, creativity, and innovation are linked to a series of factors. First is the level of skills of the workforce. A better educated workforce facilitates the generation, assimilation, and absorption of innovation, as well as the short-term adaptation and medium-term adaptability to new challenges (OECD, 2011). However, the gaps in skills (Rodríguez-Pose and Tselios, 2011) and innovative capacity (Hollanders et al., 2009) differ significantly among European regions. These differences 
have important implications not only for their productivity and economic dynamism, but also for their ability to implement Schumpeterian processes of creative destruction which are at the heart of the renovation needed in periods of deep crisis (Antonelli, 2010).

Second, in terms of ecological or adaptive resilience, the ability of regions to adjust the production mix from products for which demand has been declining to others in which it has remained stable or even increased, as well as their capacity to migrate from lower to higher value-added functions, as indicated by the literature on global commodity chains (Gereffi, 1999) are of special importance.

Third, political and institutional factors play a non-negligible role in the process of rapid adaptation but, more importantly, to the medium-term adaptability of a territory to sudden economic changes (Rodríguez-Pose, 2013). Some of the institutional factors relate to the strategic capabilities of the firms located in any given territory. Lack of leading firms and a dominance of small and/or closed, non-innovative firms seriously jeopardises the potential of territories to adapt and react to a crisis. The presence of leading enterprises, with greater contacts to the outside world, but still well 'embedded' in the region can expedite the process of adaptation (Fratesi and Senn, 2009; Rodríguez-Pose and Fitjar, 2013). Companies less 'embedded' in the region may simply relocate or reduce their production capacity more easily in the face of adversity. Hence a balance between internal and external connections becomes of paramount importance especially in period of crisis (Fratesi and Senn, 2009).

Institutional factors also contribute to determine the efficiency of public policies aimed at stemming the effects of a crisis. National and local institutional conditions affect the functioning of the labour 
market. This shapes choices made by firms and governments regarding layoffs at different stages of the crisis. Dual labour market systems and cultures contributed to the very rapid rise of unemployment in Spain in the early phases of the crisis, while flexicurity systems and collective bargaining processes assisted in softening the impact of the crisis on employment in the Nordic countries (Heyes, 2011). The quality of public policies and their effective implementation is also a consequence of local institutional arrangements and constructs (Rodríguez-Pose, 2013).

\subsection{Sheltered economies, adaptability and resilience}

A fourth often overlooked, factor which governs the capacity of regions to adapt to sudden or prolonged shocks is the presence of 'sheltered' or 'protected' economies (Trigilia, 1992; RodríguezPose and Fratesi, 2007). 'Sheltered' or 'protected' economies emerge when regions depend mainly on non-market oriented sectors. Sheltered regions have a tendency to have lower levels of employment and to rely on a swollen public sector. The idea is that there are structural conditions in sheltered regional economies which make them less exposed to market cycles, either because they have specialized in closed sectors that do not export and whose demand is very stable, or because they are protected by economic policy conditions that dampen the immediate impact of a crisis, such as a high concentration of public employment. These regions are generally "more impervious to changes in the business cycle" (Rodríguez-Pose and Fratesi, 2007: 624), meaning that they are, in theory, more protected than open regions from downturns in the cycle, but are also less ready to benefit from economic recoveries. 'Sheltered economy' regions can rely, at least at the beginning of a crisis, on a series of automatic stabilisers that soften the blow on employment. High levels of public employment and a specialisation in sectors more closed to international competition imply that employment destruction is reduced relative to other regions, so long as the state or public 
consumption levels do not collapse. The very factors that soften the initial blow may, however, not be able to protect a region from lengthy structural crises like the present one. Prolonged crises limit the resources available for public policies and shortages of public funds may, in turn, lead to redundancies in the traditionally more stable public sector, as has been the case in Greece. Also, in cases where the decline in domestic demands outstrips the decline in international demand, protected economies may suffer disproportionally.

Overall, it can be said that, while the presence of sheltered economies may be a blessing in the short-run, in the long-run these areas are bound to be ill-prepared to adapt to changes through processes of creative destruction. The likelihood is that they will often end up embroiled in vicious circles of dependency on transfers (Trigilia, 1992) and reacting in a more lethargic way than open regions (Petrakos et al., 2005). Looking at employment, it can be argued, that, at least in the initial stages of a crisis, protected regions will be less affected by recessions, meaning a lower number of layoffs, but also will experience a lower recovery in employment once the recovery starts.

\subsection{Adaptability and resilience in the empirical literature}

Although there is certainly a great interest in the economic consequences of the crisis at a regional level, the lag in the availability of regional data means that the growing number of empirical studies published in the literature still refer to the early years of the downturn. Most studies have focused on how different factors have impinged on the different levels of adaptability and resilience of regions in Europe. Martin (2012), for example, compares three British crises, underlining the importance of local economic structures for the resilience of regions. Fingleton et al. (2012) also 
focus on British regions in their analysis of the resilience to employment shocks during the period 1971-2010, indicating that the two dominating types of resilience that have characterised British regions are either 'engineering resilience', when economies have bounced back to their past equilibrium, generally after a brief shock, and 'ecological resilience', in which the crises have been associated with permanent transfers to different equilibria. Fingleton et al. (2012) find that ecological resilience changes are more likely to be associated with diverse resistances to initial shocks, rather than with developments in the recovery phase. Hence, they argue that initial shocks often tend to leave permanent effects.

Analyses covering different countries in Europe, such as the European $6^{\text {th }}$ Cohesion Report, have unveiled that the crisis brought an end to the employment convergence of the boom years and that, across Europe, there seems to have been a contrast between the employment behaviour of metropolitan versus rural regions: whereas metropolitan regions have been more prone to 'boom and bust', rural regions have been less affected in the short-term by changes in the economic cycle (European Commission, 2014). Research for the OECD confirm this view, indicating that in the first years of the crisis many rural and peripheral regions have been more resilient to changes in employment than core areas (OECD, 2011). Unemployment rose more in those regions that were more open and that had higher overall employment levels prior to the inception of the crisis (OECD, 2011). The positive trajectories of cities and the greater resilience of urban regions has often been linked to the capacity to rely on a combination of both soft (e.g. social capital, buzz) and hard (e.g. human capital, infrastructure) factors, as well as on their capacity to rely on networks and agglomeration economies. Their resilience lies in their very openness (Capello et al., 2015a and 2015b). 
The literature covering North America is admittedly more limited, perhaps reflecting the lower long-term impact of the crisis in the USA. One of the main contributions by Chapple and Lester (2010) shows that factors such as the capacity of metropolitan labour markets in the US is strongly connected to their capacity to attract and retain immigrants and to innovate in high-tech manufacturing sectors.

In this paper, rather than focusing on resilience per se, we examine the initial impact of the crisis of employment trends at the regional level. We prefer this to a fully-fledged analysis of resilience, as, on the one hand, there is still a short time series available at the regional level and, on the other, in many parts of the periphery of Europe the crisis is far from over, meaning that it is still unclear how resilient different types of regions will prove to be in the end. Moreover, as Martin and Sunley (2015: 3) indicate "there is no generally accepted methodology for how the concept [of resilience] should be operationalized and measured empirically", meaning that by not focusing on resilience we do not contribute to the risk of potential "conceptual slippages seen in other fields", stressed by Martin and Sunley (2015: 35).

We therefore analyse the differential impact of the crisis on employment in the European regions at NUTS2 level for the EU-27. ${ }^{1}$ In particular, our interest lies in how the economic behaviour of regions relative to national economic cycles in the past has affected their reaction during the crisis. Have economies which displayed a distinct sheltered economy behaviour during the period of boom

\footnotetext{
${ }^{1}$ The choice of the scale can indeed be problematic, since there is significant variation between NUTS2 regions in terms of size, administrative capacity, and political power. Some European NUTS2 regions, for example, enjoy considerable political powers, while others are nothing more than mere statistical units. However, NUTS2 has become the standard level of analysis for European regions, for pure reasons of data availability. It is also the regional level used by the European Commission to determine Cohesion Policy eligibility. By contrast, data at the level of functional areas only exist for a limited number or urban areas which do not cover all of the European territory and the time series are very limited.
} 
been able to weather better employment destruction than those that were more open? Or has their supposed lack of reaction capacity condemned them to greater levels of employment destruction?

\section{The crisis and regional employment: basic facts}

In the boom years before the crisis employment levels had steadily risen in Europe. As indicated in Figure 1, which takes 2008 as the base year, the greatest growth took place in those member-states which had joined the EU prior to 2004. Fuelled by high employment growth in Spain, these 'old' member-states went to year-on-year employment growth from 2000 until 2008. Post-2004 members were hit by the crisis of the early 2000s and by a phase of restructuring in the preaccession period. They therefore underwent a strong contraction in employment in 2001 and, to a lesser extent, in 2002 (Figure 1). But employment growth in these countries took off from 2004 until 2008. 2008 marked the peak of employment in the European Union to date. Since then employment in Europe started to rapidly decline between 2008 and 2010, until stabilising in 2011 and 2012 and marking a slight recovery in 2013. The decline in employment was bigger in the post2004 members, but so has also been the post-2011 recovery (Figure 1).

Figure 1: Evolution of total employment in Europe, pre-and post-2004 EU members Index with base year 2008=100. 


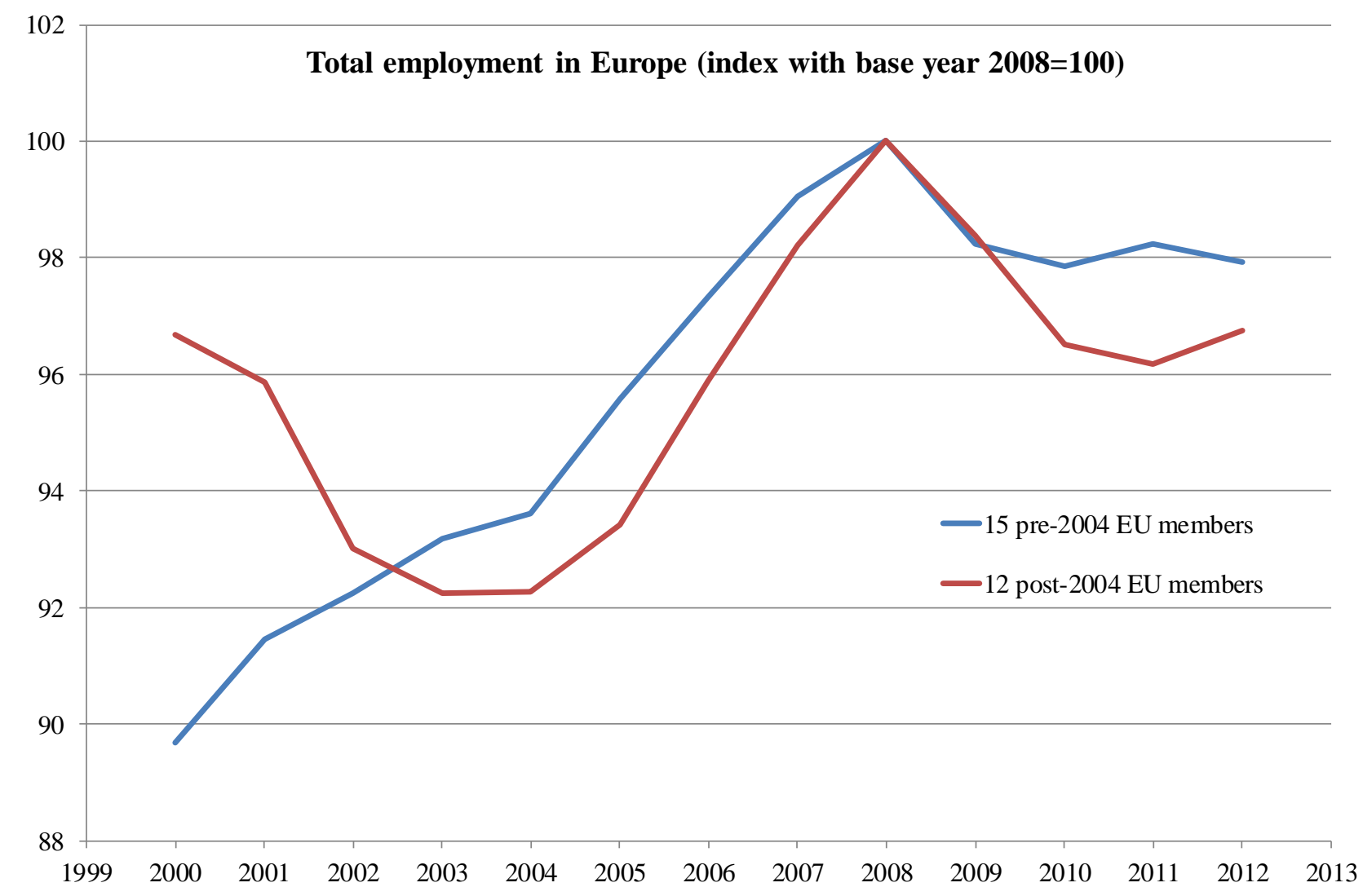

These general trends, however, hide stark geographically uneven patterns in the evolution of employment. Figure 2 presents the evolution of the employment at the regional level in Europe during the early stages of the crisis: between 2008 and 2012, representing respectively the zenith and the nadir in European employment. Each individual annual map depicts the percentage change in employment between that year and the situation in 2008, according to the following formula:

$$
\operatorname{var}_{t}=\left(\left(e m p_{t} / e m p_{2008}\right)-1\right) * 100
$$

where emp is the total number of people employed in the region and $t$ the reference year.

The figures show deep differences in the geography and timing of the employment crisis. In the year after the outbreak of the crisis, employment levels sunk in the Highlands and Islands in Scotland, Estonia, Latvia, and the Spanish Mediterranean regions of Catalonia, Murcia, and 
Valencia. Ireland, Lithuania, the rest of Spain, Italy, and the three Nordic countries also underwent considerable declines in employment. By contrast, jobs kept on growing in certain European regions, mainly in Poland (where the biggest employment growth took place), Luxembourg, Germany, France, Belgium, and even Greece. Contrasts in employment performance were stark in some countries. In Poland, Kujawsko-Pomorskie experienced the greatest job creation in that year, while the neighbouring Lódzkie region was amongst the worst performers in Europe. Strong regional contrasts in employment generation were also the norm in Austria, Belgium, France, Germany, Hungary, and the UK.

By 2010, the employment crisis took a respite in most of the core of Europe. Employment levels improved in Belgium, France, Germany, and Luxembourg. But even in these countries specific regions, such as Lower Normandy, Limousin, and Picardie in France, or Hainaut in Belgium had relatively poor performances. The employment crisis deepened in the Baltic states, Bulgaria, Hungary, Ireland, and Spain. But not the entire periphery was suffering. Corsica had the best employment performance in Europe in that year. Ipeiros in Greece, regions in northern Romania, and six of the seventeen Polish regions had still greater levels of employment than at the beginning of the crisis.

In 2011 the polarisation in employment patterns became more evident. The periphery of Europe mirroring the results of Fingleton et al. (2015) - was most affected. The Baltics (with the exception of Estonia), Bulgaria, Greece, Ireland, Portugal, and, above all, Spain had witnessed a considerable destruction of employment since 2008 (Figure 2). Some countries in the economic core, such as Denmark, Finland, and the Netherlands also endured considerable job destruction. By contrast, not 
a single German region had levels of employment below those of 2008. Similarly, Belgium, with exception of Hainaut, and Luxembourg had performed well regarding job generation.

By 2012 only Cyprus, Luxembourg, the majority of regions in Austria, Belgium, Germany, and some individual regions in mainly the Czech Republic, France, Poland, Romania, or the UK were at levels of employment above those of 2008. The biggest job destruction was found in some of the countries that were hit early by the crisis, such as Bulgaria, Ireland, Latvia, or Spain, as well as in some latecomers to the crisis in terms of employment, such as Greece and Portugal (Figure 2). 
Figure 2: Employment growth in European regions (base year 2008).
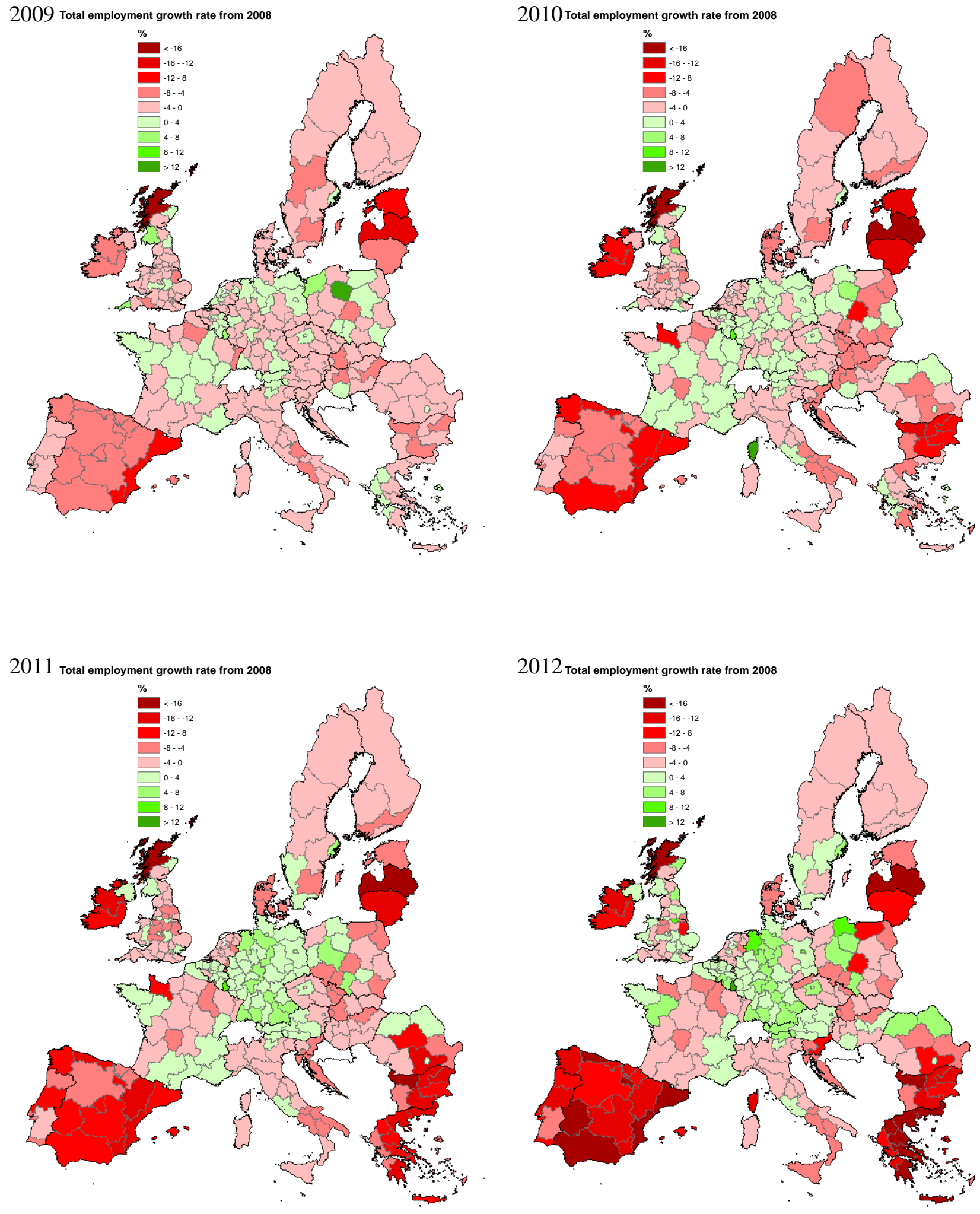
Besides the cross-country differences, there were also important within country disparities. Figure 3 maps the within-country disparities in employment trajectories between 2008 and 2012, using the following formula:

$$
\operatorname{dif}_{\mathrm{t}}=\left[\left(\mathrm{emp}_{2012}^{\mathrm{r}} / \mathrm{emp}^{\mathrm{r}}{ }_{2008}\right)-\left[\left(\mathrm{emp}^{\mathrm{n}}{ }_{2012} / \mathrm{emp}^{\mathrm{n}}{ }_{2008}\right)\right] \cdot 100\right.
$$

Figure 3 allows distinguishing between regions where employment grew above and below the national average. One of the most noticeable factors in the figure is that in virtually all European countries capital regions have been able to create more/destroy fewer jobs than the average of the country. The only exceptions have been Paris in France, Athens in Greece, Lisbon in Portugal, and Bratislava in Slovakia. Many large cities also performed relatively well in terms of employment generation. This is, for example, the case of the UK, where in a generally underperforming North of England some of the biggest northern cities - Liverpool, Manchester, and Sheffield - performed above the country average. Similarly, in Germany Hamburg, Frankfurt, Munich, as well as Milan and Rome in Italy did better than the national average (Figure 3).

In some countries, the evolution of employment during the crisis reinforced pre-existing disparities. This is the case of Italy and Spain, where a north-south polarisation has become more evident. In Germany, eastern regions (with the exception of Berlin) have performed worse, as it is generally the case of northern regions in the UK and the less developed eastern regions of Poland. However, this is not always so, as in Belgium employment trends in Wallonia have topped those of Flanders (Figure 3). 
Figure 3: Regional employment change in European regions relative to the national average (20082012).

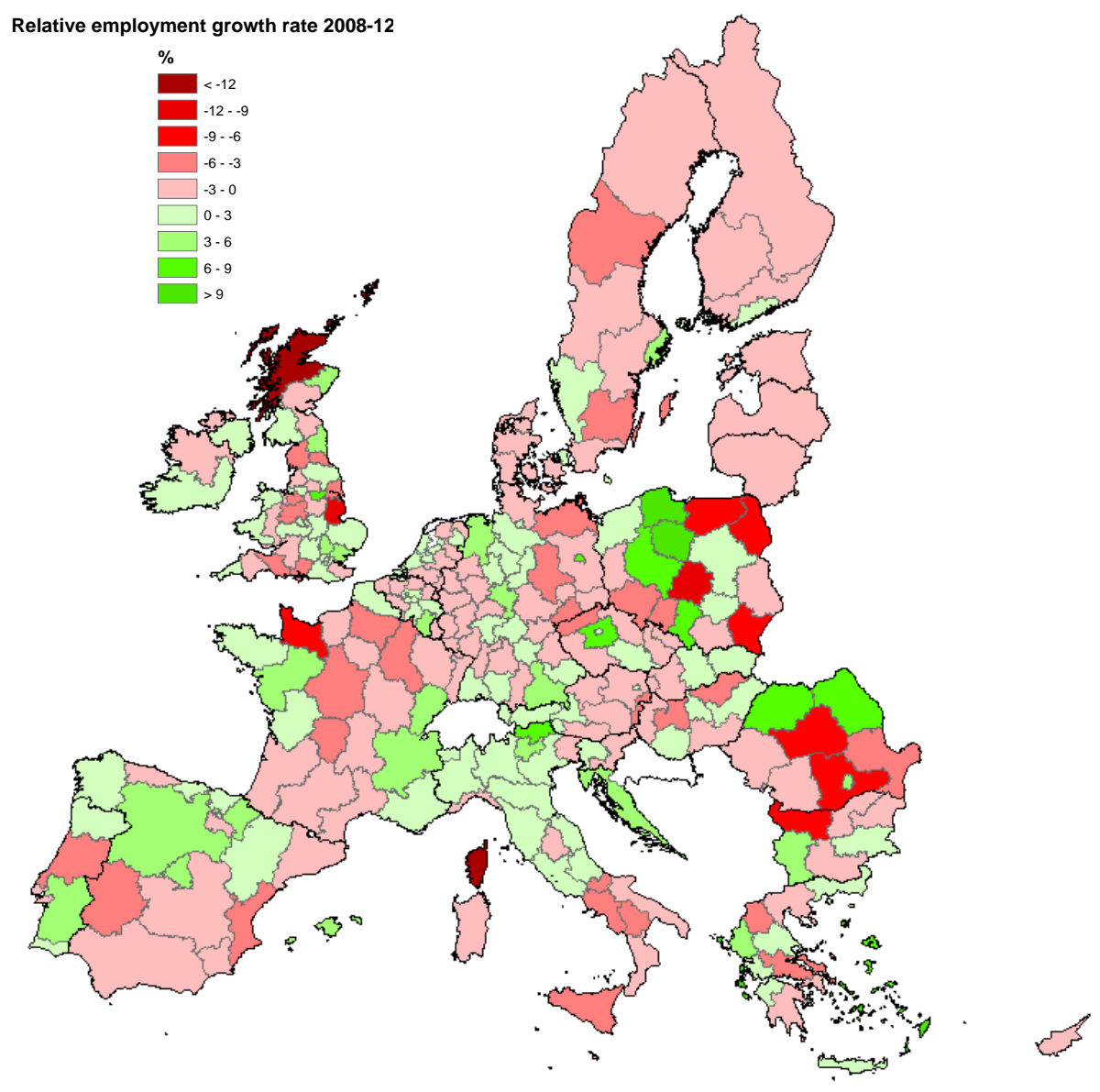

Overall, and in contradiction with some of the reports focusing on the very early stages of the crisis (e.g. OECD, 2011), the evidence presented highlights that the crisis has not been kind for many regions lagging behind. Employment destruction in these areas has tended to be larger than in the core, regardless of whether we are talking about the core of Europe or the core of each country. Much of the convergence in employment generation experienced in the boom years has been reverted since the beginning of the crisis.

\section{Sheltered economies in Europe}


In order to analyse whether the level of protection developed prior to the crisis has affected regional capacities to adapt to the current situation and bounce back in terms of employment, we first need to identify which European regions had become more sheltered in the pre-crisis period. We therefore resort to the methodology developed by Rodríguez-Pose and Fratesi (2007) for the identification of sheltered economies. This methodology involves detecting regions with a counter-cyclical behaviour, by comparing the average growth rates in periods of high and low growth, relative to the country where they are located over extended periods of time. The sheltered economy indicator is hence calculated relative to the national average, which means that it is not affected by the overall performance of the country. Hence, by definition open and sheltered regions exist in every country.

The formula used by Rodríguez-Pose and Fratesi (2007) for calculating the presence of a sheltered economy in any given region is as follows:

$$
\text { Shelt }=\text { EXP-REC }
$$

where EXP is the difference in the average growth rate in the region in years of above-average growth, and $R E C$ is the differential rate growth of the region in the years of below-average growth.

EXP and REC are, in turn, calculated as:

$$
E X P=\frac{\sum_{\text {year }=1}^{n}(\text { regional_growth }- \text { national_growth }) \cdot \mathrm{I}_{E X P}}{\sum_{\text {year }=1}^{n} \mathrm{I}_{E X P}}
$$




$$
R E C=\frac{\sum_{\text {year }=1}^{n}(\text { regional_growth }- \text { national_growth }) \cdot \mathrm{I}_{R E C}}{\sum_{\text {year }=1}^{n} \mathrm{I}_{R E C}}
$$

where $I_{\text {EXP }}$ e $I_{\text {REC }}$ are the binary indicators of national growth in years of economic expansion and recession respectively. The resulting Shelt index is positive when the regional employment growth in a given region is higher than the national average in periods of economic expansion in comparison with periods of relative crisis. This occurs in open regions which tend to be more exposed to the vagaries of the cycle and open. Negative values of the Shelt index depict regions that perform better than the national average during periods of low growth and vice versa in periods of high growth. They represent regions that follow anti-cyclical behaviours as a consequence of their lower exposure to markets and greater dependence on types of employment that are less connected to changes in market conditions.

For consistency with the objectives of the paper, changes in employment are used in order to calculate the sheltered economy (Shelt) index. Moreover, as economic cycles are neither perfectly synchronized nor regular across countries and regions in Europe, the average growth rate of employment of every country is determined using data from the years before the crisis (1995 to 2007), identifying the years in which the growth of employment was greater than the national average for EXP and those in which growth was below average for REC.

The resulting sheltered economy index at a regional level, calculated for 272 NUTS2 regions in Europe between 1995 and 2007 is plotted graphically in Figure 4. The evolution of employment levels of regions relative to their national average in years of economic expansion (EXP) is plotted on the $\mathrm{X}$-axis. Their behaviour in years of recession (REC) is represented on the $\mathrm{Y}$-axis. The figure 
can be divided into eight different sectors in order to not only to classify regions into sheltered and open, but also to better discern the relationship between the potential theoretical situations along the sheltered vs. open divide and the actual behaviour of European regions in all phases of the cycle between 1995 and 2007. Sectors 1-4 represent sheltered regions, according to the results of the index, while sectors 5-8 depict open regions. Darker shadings denote regions that are performing better than average, while lighter shadings are regions performing below average. In particular, sectors 1 and 8 depict regions which have performed better than the nation average in all phases of the cycle. Sectors 4 and 5 include regions whose employment performance has been worse than the national average in all phases of the cycle.

More specifically each sector reflects the following employments paths:

Sector 1: Sheltered regions performing above the national average in all phases of the economic cycle;

Sector 2: Sheltered regions performing above the national average, but with a worse than average performance in expansionary phases of the economic cycle;

Sector 3: Sheltered regions performing below the national average, but with a better than average performance in the recessionary phases of the economic cycle;

Sector 4: Sheltered regions performing below the national average in all phases of the economic cycle (and particularly in expansionary periods);

Sector 5: Open regions performing below the national average in all phases of the economic cycle (and particularly in recessionary periods);

Sector 6: Open regions performing below the national average, but with a better than average performance in the expansionary phases off the economic cycle. 
Sector 7: Open regions preforming above the national average, but with a worse than average performance in the recessionary phases of the economic cycle.

Sector 8: Open regions performing above the national average in all phases of the economic cycle.

Figure 4: Theoretical situations and actual behaviour of European regions in the period 19952007.

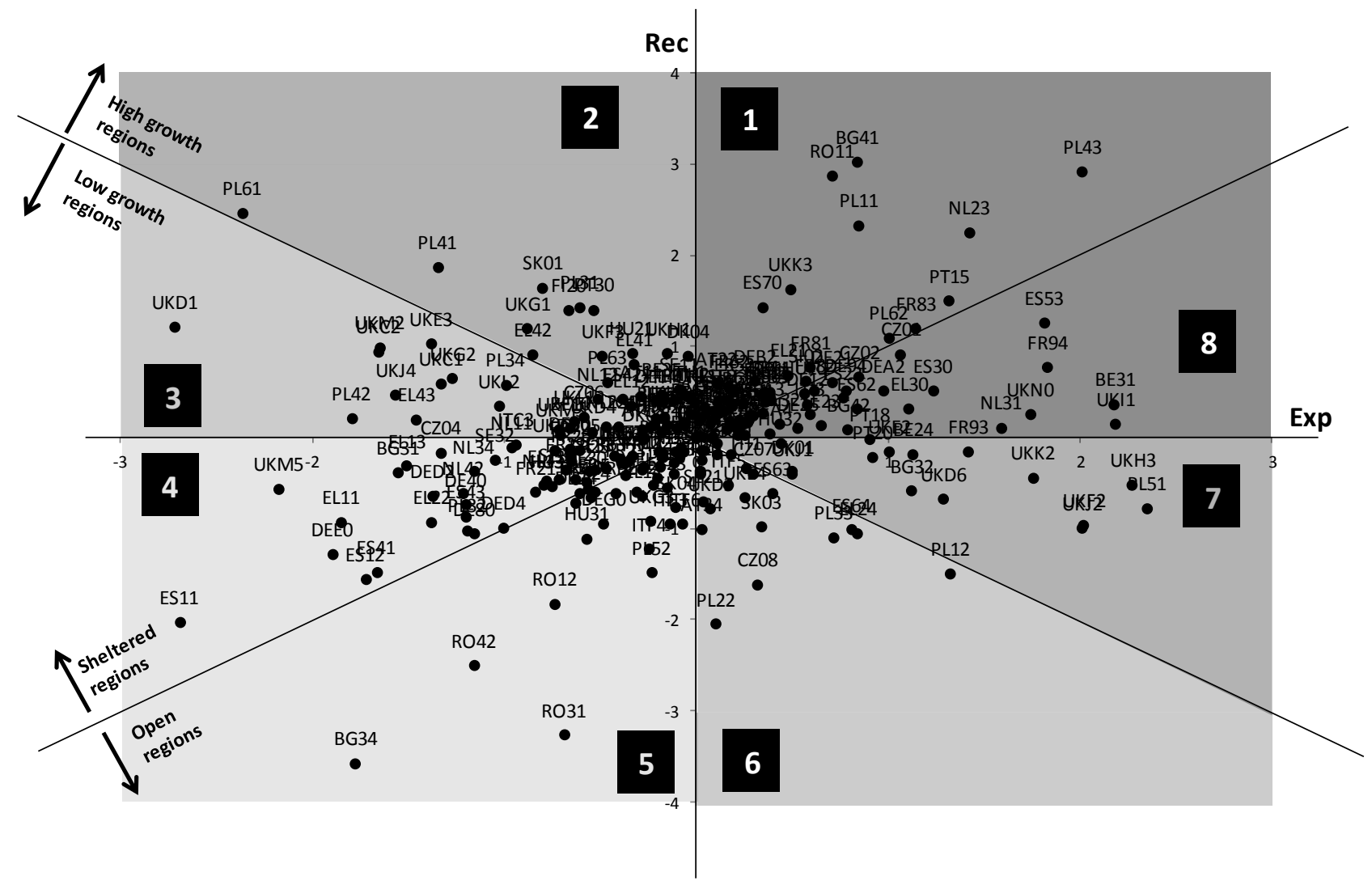

Although more European regions can be considered sheltered than open (141 out of the 252 regions considered in the analysis have a Shelt index which puts them in the sheltered category), the majority of regions is clustered around the centre of Figure 4 indicating that their employment trajectory is far from extreme. Most regions in Austria, France, Germany, and Ireland, belong to this group. In these countries there is little difference between relatively open and relatively sheltered regions, indicating overall a small presence of sheltered economies. There exists however a nonnegligible number of regions at considerable distance from where both axes meet, signalling the 
presence of more extreme cases of sheltered/open regions. Such a situation is more evident in countries like Bulgaria, Greece, Poland, Romania, Slovakia, Spain, and the UK.

Figure 5 translates the results of the sheltered economy index into a map. Several conclusions can be extracted from the visual inspection of the map. First of all, the most extreme sheltered economy cases can be found in some central and eastern European countries such as Bulgaria, Poland, Romania, and Slovakia, where the spread between sheltered and open regions is much greater than in other former transition countries (Czech Republic, Hungary, Slovenia). However, a number of 'old' member states are no strangers to wide internal differences in regional trajectories relative to the economic cycle. This is particularly the case of Greece and the UK.

Second and as a general rule, open economies tend to coincide with national capitals and core regions. This is the case across Europe, where cities like London, Paris, Madrid, Amsterdam, Brussels, Copenhagen, Athens, Warsaw, Budapest, Prague, or Dublin are more open than the average region in their country. The same applies for other large cities such as Barcelona, Frankfurt, Munich, Rotterdam, Manchester, Gothenburg, Malmö, Birmingham, Manchester, Leeds, Porto, or Marseilles. On average open regions tend to be amongst the largest regions in economic terms across European countries. For instance, in France Paris and almost all urban areas belong in the open region category. But this is far from a universal rule. Some national capitals - Berlin, Bratislava, Lisbon, Rome, Stockholm, or Vienna - display patterns of employment behaviour closer to those of sheltered economies. The same can be said of some regions hosting important cities such as Hamburg, Milan, Krakow, Lyon, or Valencia (Figure 6). 
Third, in most European countries the open/sheltered economy region gap tends to coincide with the more/less developed region gap. There are a few exceptions, with perhaps Italy being the more glaring one. In Italy, the richer and traditionally more industrialised regions of the North, as well as Lazio, the region holding the capital, had a behaviour in employment terms in the boom years more akin to those of protected economies. By contrast, the more backward southern regions followed, with the exception of Sicily and Sardinia, paths closer to those expected from open economies (Figure 6). This coincides with the results of Canale and Napolitano (2015) who find that the South of Italy, contrary to widespread belief, has been a relatively open area of Italy. They underline that "the South can be defined as sheltered when national policies switched from industrialization and investments into simple transfers" (Canale and Napolitano, 2015: 345). This only happened between 1973 and 1996. From 1996 onwards the South of Italy became moderately exposed to cyclical fluctuations, while the North was relatively sheltered.

Figure 5: Regions more and less exposed to the cycle in Europe 1995-2007.

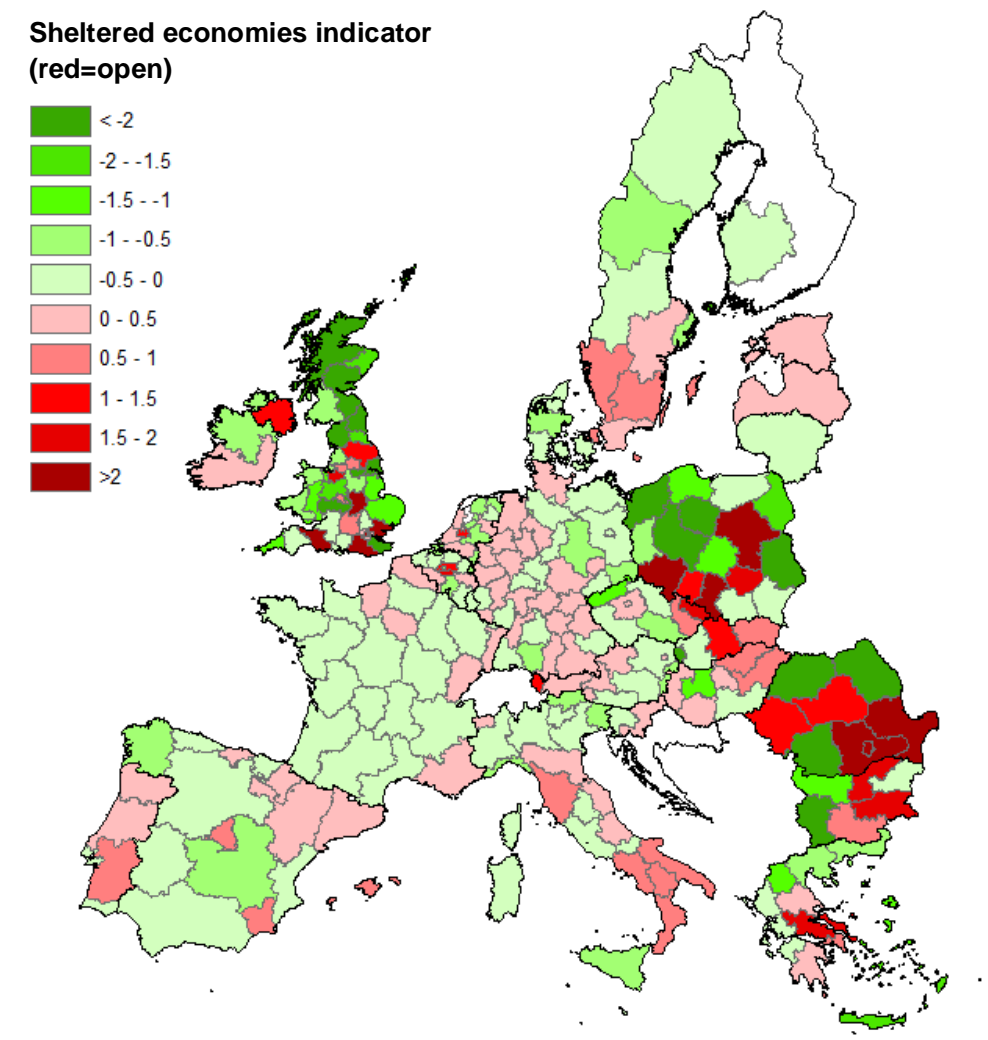




\section{Sheltered economies and employment trends during the crisis}

To what extent has the emergence of sheltered economies in many parts of the periphery of Europe and, especially, in its poorest regions affected the capacity of European regions to weather the crisis? Has a presence of sheltered economies made regions less adaptable and resilient?

The paper addresses this question by conducting two types of analysis: one more descriptive, looking at the employment trajectories since the outbreak of the crisis of regions included in the different sectors of Figure 4, followed by a more analytical approach, based on a cross-section model regressing employment change on the pre-existence of sheltered-economy-type behaviours. We present each analysis in turn.

\subsection{Descriptive analysis}

The descriptive analysis examines the extent to which the regions included in different sectors of the sheltered economy index (Figure 5) have had different trajectories in terms of employment generation/destruction since the outbreak of the crisis. The aim is to unveil patterns relating the emergence or consolidation of sheltered economies in the pre-crisis period with employment change in the period 2008-2012. The analysis includes an Anova test to determine if the behaviours of the groups of regions included in the different sectors are statistically different. The results are reported in Table 1, which first divides regions in the EU according to a combination of their sheltered index and their performance (sheltered and dynamic, in sectors $1 \& 2$; sheltered and less dynamic, in sectors $3 \& 4$; open and less dynamic, in sectors $5 \& 6$, open and dynamic, in sectors $7 \& 8$ ), before 
looking at the employment performance of each sector individually. All results in Table 1 report strongly significant F-tests, allowing us to statistically exclude that pre-crisis behaviour is not correlated to the behaviour during the initial years of the crisis.

The results of the descriptive analysis highlight that the best - or, at least, less bad - employment performances during the first years of the crisis correspond to the two extremes. Between 2008 and 2012 there is less employment destruction both in those regions that had a greater degree of openness or a greater degree of protection, but which had had a better employment performance in the years prior to the crisis (Sectors $1 \& 2$ and 7\&8) (Top of Table 1). By contrast, the worst employment performances are found in sheltered and open regions that had also endured worse employment performances in the boom years (Sectors $3 \& 4$ and 5\&6) (Table 1). This implies the emergence of a certain degree of path dependency: regions that were more competitive in employment generation in the pre-crisis period have remained also more dynamic since the beginning of the crisis. More open regions in the boom years have also tended to perform better in terms of employment during the crisis, although this trend is not as marked as that concerning previous employment dynamism.

By descending to a finer level of aggregation, it becomes evident that more sheltered and less dynamic regions (Sectors 3 and 4) experience the worse overall performance. They are followed closely by regions in Sector 5, open but less dynamic in the run-up to the crisis. The best employment performances during the crisis are found among more open regions with good employment trajectories prior to the crisis (Sectors 7 and 8), but also in highly protected regions with good past trajectories (Sector 2) (Table 1). Indeed, it is the highly sheltered regions of Sector 2 which experience the best overall employment performance - albeit by a whisker relative to the open regions of Sector 7. From this descriptive analysis emerges a picture of less employment 
destruction at both extremes of the open/sheltered continuum. The best performances found in open dynamic economies, but also in those highly protected economies which had good performance in the past. It is the regions in-between these extremes which seem to have suffered the brunt of the employment crisis.

This behaviour may be the result of the inclusion in the sample of a number of post-2004 EU members. The large majority of the countries that joined the EU since 2004 were former communist economies which underwent a deep transition process. They also experience higher economic rates in the 2000s. Both factors put together may mean that the deep structural adjustments of transition and the ensuing rapid growth may have affected employment generation in many of these countries and their respective regions, consequently altering the calculations and meaning of what is considered to be a sheltered economy. We therefore re-estimate the analysis presented in Table 1 for the 15 members of the EU pre-2004. The results of the estimation are displayed in Table 2. The results are robust to this change in the composition of the sample. Once again sectors $1 \& 2$ and $7 \& 8$ display the best performance in terms of more limited employment destruction, while the worst overall performance is found in sheltered and less dynamic regions (sectors $3 \& 4$ and, in particular, in sector 3) (Table 2). The only meaningful difference relates to the significance of the F-test for the 8-sector employment growth 2008-2012 in absolute terms, which drops in value. However, the differences, once national averages are taken into account, remain strongly significant. The orders are in all cases unaffected, meaning that these results are not driven by the patterns of post-2004 EU members. 
Table 1: growth or decline in employment in European regions in the period 2008-2012 according to their behaviour in the previous period

\begin{tabular}{|c|c|c|c|c|c|c|}
\hline \multirow[t]{2}{*}{ Sectors } & \multirow[t]{2}{*}{ Type of Regions } & \multicolumn{2}{|c|}{$\begin{array}{r}\text { Employment growth } \\
2008-2012\end{array}$} & \multicolumn{2}{|c|}{ Employment growth } & \multirow[t]{2}{*}{$\begin{array}{r}\text { Number } \\
\text { of } \\
\text { regions }\end{array}$} \\
\hline & & Mean & Standard Dev. & Mean & Standard Dev. & \\
\hline $1 \& 2$ & Sheltered and strong & -1.53 & 6.55 & 0.54 & 4.65 & 71 \\
\hline $3 \& 4$ & $\begin{array}{r}\text { Sheltered and less } \\
\text { dynamic }\end{array}$ & -4.53 & 7.24 & -1.56 & 4.63 & 70 \\
\hline $5 \& 6$ & Open and less dynamic & -3.44 & 6.31 & -0.66 & 2.92 & 57 \\
\hline \multirow[t]{2}{*}{$7 \& 8$} & Open and dynamic & -1.19 & 7.00 & 1.03 & 3.40 & 54 \\
\hline & Total & -2.72 & 6.89 & -0.21 & 4.16 & 252 \\
\hline F-test & & 3.5 & & 5.34 & & \\
\hline Prob $>F$ & & 0.0162 & & 0.0014 & & \\
\hline \multirow[t]{2}{*}{ Sectors } & \multirow[t]{2}{*}{ Type of Regions } & \multicolumn{2}{|c|}{$\begin{array}{r}\text { Employment growth } \\
2008-2012\end{array}$} & \multicolumn{2}{|c|}{$\begin{array}{r}\text { Employment growth } \\
2008-2012 \\
\text { with respect to country }\end{array}$} & $\begin{array}{r}\text { Number } \\
\text { of } \\
\text { regions }\end{array}$ \\
\hline & & Mean & Standard Dev. & Mean & & \\
\hline 1 & $\begin{array}{r}\text { Sheltered and dynamic } \\
(\exp >0)\end{array}$ & -2.28 & 7.07 & -0.07 & 4.39 & 36 \\
\hline 2 & $\begin{array}{r}\text { Sheltered and dynamic } \\
(\exp <0)\end{array}$ & -0.76 & 5.98 & 1.17 & 4.88 & 35 \\
\hline 3 & $\begin{array}{r}\text { Sheltered and less } \\
\text { dynamic }(\text { rec }>0)\end{array}$ & -4.45 & 7.79 & -2.24 & 5.90 & 24 \\
\hline 4 & $\begin{array}{r}\text { Sheltered and less } \\
\text { dynamic }(\text { rec }<0)\end{array}$ & -4.56 & 7.03 & -1.21 & 3.83 & 46 \\
\hline 5 & $\begin{array}{r}\text { Open and less dynamic } \\
\qquad(\exp <0)\end{array}$ & -4.32 & 6.75 & -1.06 & 2.85 & 32 \\
\hline 6 & $\begin{array}{r}\text { Open and less dynamic } \\
(\exp >0)\end{array}$ & -2.32 & 5.62 & -0.15 & 2.99 & 25 \\
\hline 7 & $\begin{array}{r}\text { Open and dynamic } \\
(\text { rec }<0)\end{array}$ & -2.21 & 6.85 & 1.15 & 5.53 & 15 \\
\hline 8 & $\begin{array}{r}\text { Open and dynamic } \\
(\mathrm{rec}>0)\end{array}$ & -0.80 & 7.10 & 0.99 & 2.20 & 39 \\
\hline & Total & -2.72 & 6.89 & -0.21 & 4.16 & 252 \\
\hline F-test & & 1.86 & & 2.77 & & \\
\hline Prob $>F$ & & 0.0774 & & 0.0088 & & \\
\hline
\end{tabular}


Table 2: growth or decline in employment in European regions in the period 2008-2012 according to their behaviour in the previous period (ONLY EU15)

\begin{tabular}{|c|c|c|c|c|c|c|}
\hline \multirow[t]{2}{*}{ Sectors } & \multirow[t]{2}{*}{ Type of Regions } & \multicolumn{2}{|c|}{$\begin{array}{r}\text { Employment growth } \\
2008-2012\end{array}$} & \multicolumn{2}{|c|}{$\begin{array}{r}\text { Employment growth } \\
2008-2012 \\
\text { with respect to country }\end{array}$} & \multirow[t]{2}{*}{$\begin{array}{r}\text { Number } \\
\text { of } \\
\text { regions }\end{array}$} \\
\hline & & Mean & Standard Dev. & Mean & Standard Dev. & \\
\hline $1 \& 2$ & Sheltered and strong & -1.14 & 6.44 & 0.55 & 4.21 & 53 \\
\hline $3 \& 4$ & $\begin{array}{r}\text { Sheltered and less } \\
\text { dynamic }\end{array}$ & -4.43 & 7.35 & -1.46 & 4.79 & 62 \\
\hline $5 \& 6$ & Open and less dynamic & -3.35 & 7.26 & -0.62 & 2.36 & 38 \\
\hline \multirow[t]{2}{*}{$7 \& 8$} & Open and dynamic & -0.82 & 6.81 & 1.05 & 3.38 & 47 \\
\hline & Total & -2.50 & 7.10 & -0.18 & 4.05 & 200 \\
\hline F-test & & 3.35 & & 4.47 & & \\
\hline Prob $>$ F & & 0.02 & & 0.0046 & & \\
\hline \multirow[t]{2}{*}{ Sectors } & \multirow[t]{2}{*}{ Type of Regions } & \multicolumn{2}{|c|}{$\begin{array}{r}\text { Employment growth } \\
2008-2012\end{array}$} & \multicolumn{2}{|c|}{$\begin{array}{r}\text { Employment growth } \\
2008-2012 \\
\text { with respect to country }\end{array}$} & $\begin{array}{r}\text { Number } \\
\text { of } \\
\text { regions }\end{array}$ \\
\hline & & Mean & Standard Dev. & Mean & & \\
\hline 1 & $\begin{array}{r}\text { Sheltered and dynamic } \\
(\text { exp>0) }\end{array}$ & -1.36 & 6.86 & -0.01 & 3.75 & 27 \\
\hline 2 & $\begin{array}{r}\text { Sheltered and dynamic } \\
\qquad(\exp <0)\end{array}$ & -0.92 & 6.11 & 1.13 & 4.64 & 26 \\
\hline 3 & $\begin{array}{r}\text { Sheltered and less } \\
\text { dynamic }(\text { rec }>0)\end{array}$ & -4.88 & 8.26 & -2.58 & 6.25 & 21 \\
\hline 4 & $\begin{array}{r}\text { Sheltered and less } \\
\text { dynamic }(\text { rec }<0)\end{array}$ & -4.20 & 6.93 & -0.89 & 3.81 & 41 \\
\hline 5 & $\begin{array}{r}\text { Open and less dynamic } \\
(\exp <0)\end{array}$ & -3.76 & 7.63 & -0.48 & 2.13 & 23 \\
\hline 6 & $\begin{array}{r}\text { Open and less dynamic } \\
(\text { exp>0) }\end{array}$ & -2.72 & 6.87 & -0.82 & 2.73 & 15 \\
\hline 7 & $\begin{array}{r}\text { Open and dynamic } \\
(\text { rec }<0)\end{array}$ & -1.26 & 6.43 & 1.68 & 5.89 & 12 \\
\hline 8 & $\begin{array}{r}\text { Open and dynamic } \\
(\mathrm{rec}>0)\end{array}$ & -0.66 & 7.02 & 0.84 & 2.02 & 35 \\
\hline & Total & -2.50 & 7.10 & -0.18 & 4.05 & 200 \\
\hline F-test & & 1.48 & & 2.51 & & \\
\hline Prob $>F$ & & 0.1782 & & 0.0173 & & \\
\hline
\end{tabular}




\subsection{Multivariate analysis}

The descriptive analysis delivers interesting results, but raises the question of how robust are the identified relationships to the introduction of other factors that may have affected employment growth during the crisis. We therefore resort to a multivariate analysis to test the robustness of the previously identified results. This type of analysis allows us to take into account simultaneously a multiplicity of factors, providing more reliable information with respect to simple univariate or bivariate descriptive analysis.

Limited data availability leads us to the estimation of a cross-section rather than a panel data model. This is due to the fact that the sheltered economy indicator needs to be calculated over long periods of time, at least covering one or two full economic cycles, so as not to render it meaningless and to prevent our index from the risk of becoming ahistorical (Martin and Sunley, 2015). The indicator is calculated with respect to the average annual growth rate and any shorter time span will imply significant bias, as, in the case of short-time spans, the average growth rate can end up being above or below the long-run growth rate. This would make it impossible to really differentiate between truly expansionary and recessionary years. With the available European datasets, it is therefore not possible to build a sheltered economy indicator panel, as the short-time span of regional data available prevents us from adopting such an approach. ${ }^{2}$

Since the aim of the paper is to analyse the overall effects of the crisis in employment, running a panel with a time coverage of only four years would risk capturing more the volatility and margin of error of regional statistics - which are considerably higher than at the national level - than any structural relationships. This drawback offsets any potential advantages linked to the possibility of

\footnotetext{
${ }^{2}$ Similarly, it does not make sense to build a panel in which the impact of the sheltered indicator is time-invariant, in a Hausman-Taylor framework. The independent variable - employment growth during the crisis - is also better captured over the full span of the crisis, rather than annually. This is because of our intention to concentrate on structural change rather than on short-time fluctuations. Finally, building a panel averaging over 4-year spans would leave only the last estimation period of crisis, making such an approach not meaningful to study the crisis.
} 
identifying causal relationships. Given these constraints, adopting a multivariate cross-section regression analysis of the type which has been used in beta convergence analysis represents the only viable econometric option. It also reinforces the descriptive analysis, as it allows to present correlations which are tested against the presence of structural characteristics of regions.

All control variables are lagged and normally refer to structural variables before the estimation period (normally in year 2000). Once again, to account for spatial heterogeneity, the estimations were produced for the EU27 and for the EU15 separately, while conducting the estimation for the EU12 was not possible due to the limited amount of regions involved. Finally, in order to address the potential issue of endogeneity, we resort to an instrumental variable analysis using a historical variable depicting whether a region was Christianised in $600 \mathrm{AD}$ as our instrument. This instrument is correlated with the endogenous explanatory variable, but not to the error term. However, the instrument is only available for Western Europe, meaning that it can only be employed for the first 15 members of the EU, which however represent a large majority of EU NUTS2 regions.

The estimated model adopts the following forms:

$$
\begin{aligned}
& \text { empgrowt }_{2008-12} \\
& =f(\text { regional characteristics } \\
& 1995-2007
\end{aligned}
$$

where empgrowth is the growth in total employment between 2008 and 2012; the regional characteristics include the presence of sheltered economies and/or dynamic economies in the boom years, as identified in the sectors of Figure 5, which is our variable of interest; the controls are regional endogenous structure variables of territorial capital, which may be expected to have affected employment change. The latter variables are used as control variables. Finally, as macroeconomics and regional structure is likely to strongly determine the performance of regional 
economies, we introduce a series of 26 country dummies, in order to control for national-specific factors. These national specific factors control for factors such as the level of decentralisation and the autonomy awarded to the different regions within the country, national economic performance, as well as for changes in specific public policies during the outset of the crisis. Including the country dummies, however, is similar to estimating a model in which the dependent variable is a growth differential meaning that all countries with only one region are excluded from this part of the analysis. The estimates use robust standard errors and are tested for the presence of spatial autocorrelation in the residuals. No violation of basic assumptions is detected. This was expected in the case of spatial autocorrelation, as the inclusion of country dummies is bound to capture proximity effects associated to regions belonging to the same country.

A large number of possible control variables have been tested (including FDI, different specialization variables, regional settings, etc.) and, after considering their significance and the correlation among them, the following control variables have been included in the analysis:

- Share of employment in agriculture, introduced as a proxy of the economic structure of the region. We expect this variable to be negatively associated with employment growth;

- Proportion of those employed in science and technology relative to the population of a region. This variable is a proxy for the innovation capacity of a region. The expectations is for this variable to have a positive coefficient, as a greater innovative capacity in a region should allow it to weather any economic crisis better, by making a territory more capable to rapidly implement processes of creative destruction.

- The share of clerks (as defined in the ISCO classification) as an indicator of the degree of specialisation of a region in services. We expect this variable to be positively associated to employment growth, as the brunt of the crisis was suffered by manufacturing, rather than 
services and many service jobs, not least in the public sector, can be considered as a refuge in a downturn.

The regression results for EU27 are reported in Table 3. All the models are significant $(\mathrm{F}>=37)$ and account for a large percentage of the variation in employment change during the crisis $\left(\mathrm{R}^{2}\right.$ always higher than $70 \%$ ).

The signs and significance of the coefficients for the control variables are generally as expected. The share of employment in science and technology is positively and significantly correlated to employment growth, as is the share of clerks. Employment in agriculture is not significant (Table 3). All country dummies are strongly significant, reinforcing the idea that labour markets are still mainly governed by national factors and tend to follow national, rather than European patterns in their evolution.

A dummy indicating whether the region had experienced levels of employment growth above the national average between 1995 and 2007 is included in regressions 2, 4, and 5. The positive and significant coefficient for this variable indicates that regions which had experienced better than average employment growth during the boom years have, ceteris paribus, performed better during the crisis than those that had had a more lacklustre performance beforehand. Although full causal testing is not possible, this correlation makes it very likely that pre-crisis competitive factors have acted in a path dependent way leading to less employment destruction during the crisis. As the coefficient for this variable ranges from 1.08 and 1.5 (Table 2), regions that had experienced a better employment trend during the boom years, have also on average been able to increase 
employment by more (or, more commonly during the crisis, reduce it by less) than $1 \%$ relative to the average of the country.

Regressions 3 and 4 test the correlation between the presence of sheltered economies and employment change. The coefficient for the variable Shelt is negative and significant in both cases, meaning that, ceteris paribus, regions that had been more protected from the market during the period 1995-2007 have, on average, endured a greater rate of job destruction than more open regions. In other words, more protected regions of the pre-crisis period, keeping structural conditions constant, have been less able to withstand the decline in employment shock associated to the early stages of the crisis (2008-2012).

When the regional pre-crisis employment performance is regressed together with the presence of sheltered economies (Regression 4), the results confirm those of Regressions 2 and 3. Both coefficients remain significant with the same signs, underling that regional employment trends during the crisis have been strongly associated with the employment dynamism and level of market protection of regions in the period immediately before the start of the downturn.

Finally, regressions 5 and 6 estimate the extent to which the correlation of the Shelt indicator with employment trends during the crisis is related to the fact that certain types of sheltered regions are more resilient in times of crisis. The regressions are run with (Regression 5) and without (Regression 6) the regional employment dynamism variable. The coefficient is not significant for exp, but positive and significant for $r e c$. This means that, while, as indicated earlier, the development of a sheltered economy in the pre-crisis years has generally been connected with a 
weakened capacity of regions to adjust to the crisis in terms of employment, those areas of Europe with the highest level of protection from the market have experienced less of an employment shock in the first years of the crisis. The absolute value of the rec coefficient varies depending on the inclusion of the variable of pre-crisis employment dynamism, but overall the coefficients indicate that those regions that during the in the boom years of the period 1995-2007 displayed the highest level of sheltered economy behaviour, as well as a greater employment dynamism in the years in which employment growth was below the average of the period, have also performed better during the crisis than their respective national average by roughly 0.5 percentage points. Being highly shielded from the market has acted as a sort of protection for these regions, guarding them, at least in the short-term, from the worse of employment destruction. Hence, we can presume that the same factors which determined the employment dynamism of regions during the period of economic expansion seem to be at play in softening/enhancing the employment effects of the economic crisis. 
Table 3: Regression results. Dependent variable: employment growth in period 2008-2012

\begin{tabular}{|c|c|c|c|c|c|c|c|c|c|c|c|c|}
\hline & (1) & & (2) & & (3) & & (4) & & (5) & & (6) & \\
\hline $\begin{array}{l}\text { Share of employment in } \\
\text { agriculture }\end{array}$ & -0.0466 & & -0.0357 & & -0.0855 & & -0.0685 & & -0.0687 & & -0.0778 & \\
\hline $\begin{array}{l}\text { Human resources in } \\
\text { Science and Technology }\end{array}$ & 0.3161 & $* *$ & 0.2767 & $* *$ & 0.3416 & $* * *$ & 0.3026 & $* *$ & 0.2922 & $* *$ & 0.2931 & $* *$ \\
\hline Share of Clerks & 134.2166 & $* *$ & 117.7305 & $* *$ & 122.705 & ** & 110.7311 & ** & 108.2887 & $* *$ & 109.9325 & $* *$ \\
\hline $\begin{array}{l}\text { Regions growing above } \\
\text { the national average } \\
(1995-2007)\end{array}$ & & & 1.5015 & $* * *$ & & & 1.2959 & $* * *$ & 1.0792 & * & & \\
\hline Shelt & & & & & -0.4623 & $* *$ & -0.3717 & $*$ & & & & \\
\hline Exp & & & & & & & & & -0.2355 & & -0.0273 & \\
\hline Rec & & & & & & & & & 0.4742 & $*$ & 0.7132 & $* * *$ \\
\hline Country dummies & $\begin{array}{l}\text { Included } \\
\text { and } \\
\text { significant }\end{array}$ & & $\begin{array}{l}\text { Included } \\
\text { and } \\
\text { significant }\end{array}$ & & $\begin{array}{l}\text { Included } \\
\text { and } \\
\text { significant }\end{array}$ & & $\begin{array}{l}\text { Included } \\
\text { and } \\
\text { significant }\end{array}$ & & $\begin{array}{l}\text { Included } \\
\text { and } \\
\text { significant }\end{array}$ & & $\begin{array}{l}\text { Included } \\
\text { and } \\
\text { significant }\end{array}$ & \\
\hline Constant & -0.7455 & & -1.7634 & & 0.6024 & & -0.5402 & & -0.4452 & & 0.3264 & \\
\hline $\mathrm{N}$ & 223 & & 223 & & 223 & & 223 & & 223 & & 223 & \\
\hline F & 46.9532 & & 45.2926 & & 45.4718 & & 44.392 & & 41.5762 & & 41.2049 & \\
\hline $\mathrm{r} 2$ & 0.7331 & & 0.7453 & & 0.7423 & & 0.751 & & 0.7514 & & 0.7476 & \\
\hline Spatial tests & $\begin{array}{l}\text { Not } \\
\text { significant }\end{array}$ & & $\begin{array}{l}\text { Not } \\
\text { significant }\end{array}$ & & $\begin{array}{l}\text { Not } \\
\text { significant }\end{array}$ & & $\begin{array}{l}\text { Not } \\
\text { significant }\end{array}$ & & $\begin{array}{l}\text { Not } \\
\text { significant }\end{array}$ & & $\begin{array}{l}\text { Not } \\
\text { significant }\end{array}$ & \\
\hline
\end{tabular}


Table 4: IV Regression results. Dependent variable: employment growth in period 2008-2012 (only EU15)

\begin{tabular}{|c|c|c|c|c|c|c|c|c|c|c|c|c|}
\hline & (1) & & (2) & & (3) & & (4) & & (5) & & (6) & \\
\hline agriculture & -0.0366 & & -0.0055 & & -0.1698 & $*$ & -0.1560 & $*$ & -0.0085 & & -0.0108 & \\
\hline $\begin{array}{l}\text { Human resources in } \\
\text { Science and Technology }\end{array}$ & 0.3958 & $* * *$ & 0.3859 & $* * *$ & 0.4935 & $* *$ & 0.4405 & $*$ & 0.4070 & $* * *$ & 0.4084 & $* * *$ \\
\hline Share of Clerks & 143.778 & $* * *$ & 130.801 & $* *$ & 66.365 & $*$ & 54.779 & $*$ & 131.994 & $* *$ & 132.435 & $* *$ \\
\hline $\begin{array}{l}\text { Regions growing above } \\
\text { the national average } \\
(1995-2007)\end{array}$ & & & 1.4096 & $* * *$ & & & 1.2678 & $* * *$ & 1.6290 & $* * *$ & & \\
\hline Shelt & & & & & -0.5881 & & -0.3191 & & & & & \\
\hline Exp & & & & & & & & & -0.2262 & & 0.0969 & \\
\hline $\operatorname{Rec}$ & & & & & & & & & -0.0641 & & 0.7035 & $*$ \\
\hline Country dummies & $\begin{array}{l}\text { Included } \\
\text { and } \\
\text { significant }\end{array}$ & & $\begin{array}{l}\text { Included } \\
\text { and } \\
\text { significant }\end{array}$ & & $\begin{array}{l}\text { Included } \\
\text { and } \\
\text { significant }\end{array}$ & & $\begin{array}{l}\text { Included } \\
\text { and } \\
\text { significant }\end{array}$ & & $\begin{array}{l}\text { Included } \\
\text { and } \\
\text { significant }\end{array}$ & & $\begin{array}{l}\text { Included } \\
\text { and } \\
\text { significant }\end{array}$ & \\
\hline Constant & -5.3006 & $* *$ & -5.7137 & $* *$ & -2.1119 & & -2.1721 & $* *$ & -5.9816 & $* *$ & -5.0663 & $*$ \\
\hline $\mathrm{N}$ & 180 & & 180 & & 180 & & 180 & & 180 & & 180 & \\
\hline $\mathrm{F}$ & 66.98 & & 62.9633 & & 56.2046 & & 57.7070 & & 56.8635 & & 54.2725 & \\
\hline $\mathrm{r} 2$ & 0.8108 & & 0.8203 & & 0.7740 & & 0.7914 & & 0.8208 & & 0.8145 & \\
\hline Spatial tests & $\begin{array}{l}\text { Not } \\
\text { significant }\end{array}$ & & $\begin{array}{l}\text { Not } \\
\text { significant }\end{array}$ & & $\begin{array}{l}\text { Not } \\
\text { significant }\end{array}$ & & $\begin{array}{l}\text { Not } \\
\text { significant }\end{array}$ & & $\begin{array}{l}\text { Not } \\
\text { significant }\end{array}$ & & $\begin{array}{l}\text { Not } \\
\text { significant }\end{array}$ & \\
\hline
\end{tabular}


In order to test whether this pattern was driven by pre-2004 or post-2004 members of the EU, the estimations were performed again for the sub-set of the 15 pre-2004 members of the EU alone as former transition economies are qualitatively different in terms of structure, dynamics, and policies towards lagging regions. The estimation was performed using an instrumental variable approach, using whether a region was Christianised in the early Middle Ages as instrument (Table 4). Table 4 shows that most coefficients remain very similar to those reported in Table 3. First, the coefficients for the controls remain virtually unchanged. Second, pre-crisis employment performance is a strong predictor of how employment in a given region fared during the crisis. Nevertheless, the negative coefficients for sheltered economies become insignificant (Table 4, regressions 3 and 4). This means that the regions which were economically dynamic before the crisis have been weathering the crisis better than those whose performance in pre-crisis Europe was worse, while those regions which were protected before the crisis did not experience a different behaviour in the EU15. This implies that the relation between the presence of sheltered economies and employment trajectories in the crisis has been weaker in the EU15 than in the EU12, possibly because of the presence of a larger level of employment in the public sector in Western Europe than in central and Eastern Europe.

\section{Conclusions}

This paper has assessed how the deep economic crisis which has struck Europe since 2008 has affected regional employment trajectories in Europe. The focus on employment is related to the fact that although employment change and its antagonist, unemployment, are two of the most visible socioeconomic consequences of any crisis, much of the analysis conducted so far 
has concentrated on economic growth, debts, or deficits. The paper has also looked at this impact at a regional level, a geographical dimension that has often been neglected, but which offers interesting nuances in a crisis which has had a greatly differentiated impact, not only at across nations, but also among regions within the same country.

The paper clearly shows that this is the case: the employment impact of the crisis has been felt in very different ways across European regions. Considerable national and regional differences in intensity and timing are in evidence. Different theoretical factors may explain why this is the case. However, the results of the analysis indicate that the presence of both dynamic and sheltered economies during the pre-crisis years has clearly been associated with the adaptability of regions to the changing trends, especially in the pre-2004 EU countries.

Regions which had developed more sheltered economies over time have, everything else being equal, tended to perform, on average, worse in terms of employment change than more open economies. Greater employment destruction has taken place in sheltered regions than in open regions. The development of sheltered economies in the years of economic expansion made more protected regions less capable of fending off the factors behind the crisis than more open economies. Their level of adaptability has been, therefore, brought down by long periods of protection from market forces. Protected economies which have been able to better withstand the economic troughs of the pre-crisis cycle, have been less capable of escaping unscathed from the troughs of a longer and deeper economic crisis. The severity of the crisis is rendering the standard protection mechanisms ineffective. 
By contrast, open regions have managed to get through the crisis in generally better shape than more sheltered economies. The only exception is related to those regions with the highest level of protection and which also witnessed greater employment dynamism in the years prior to the crisis. These regions have not only suffered less employment destruction than other sheltered regions, they have also performed better than any other category of regions identified in the analysis, sheltered or open.

In many ways, the effect of having developed a more or less sheltered economy prior to the crisis is tempered by the dynamism in employment generation prior to the start of the crisis. More dynamic and fast growing regions in the years of economic expansion developed a path dependency which has made them more adaptable to changes during the crisis. The past, therefore, matters: regions - sheltered or not - which were better equipped for generating employment growth have also been able to withstand better the factors that wreaked havoc in employment levels in those regions that had become much more lethargic in the pre-crisis years.

Overall, the analysis has put in evidence the emergence of sheltered economies has far from prepared regions for the shocks associated to the economic crisis. Developing an open and dynamic economic system has, by contrast, made regions more adaptable and capable of withstanding employment shocks better. Even in the case where high levels of protection from market have been able of stemming massive job destructions in the early stages of the crisis, the lower adaptability of these regions raises questions about their capacity in the longrun to preserve the employment levels they maintained in the first four years since the outbreak of the crisis. 
The results of analysis draw important policy implications for regional policy. Regional policy should focus on making lagging regions more open, dynamic, and competitive, rather than shelter them from the market. As our analysis shows, protecting regions, often in the periphery of Europe, has made them more impervious to standard downturns, while hampering growth and employment generation in periods of economic recovery. Sheltered regions are much more vulnerable to prolonged economic crises and transforming many of the sheltered regions in the periphery of Europe into open and competitive regions will, in all likelihood, build greater resilience in terms of employment generation into the system.

The analysis has unveiled an important connection between sheltered economies and the low dynamism of protected regions during the initial stages of the crisis. It has also uncovered the presence of a certain path dependency, as regions which created the most employment prior to the outbreak of the crisis have also been those which have been less affected by it. However, a number of questions remain unanswered and would require further analysis. These would include the factors which determine why regions become sheltered from the market in the first place, going beyond the factual approach adopted in this paper into a more structural analysis. Moreover, the link between the presence of pre-crisis sheltered economies and the capacity of regions to recover and generate new employment will acquire much greater interest. As the crisis hopefully draws closer to its end these questions will acquire more salience and will require revisiting this type of analysis once data on employment generation becomes available. 


\section{Acknowledgements}

We would like to thank the editors in charge as well as three anonymous reviewers for incisive and useful changes to earlier versions of the paper. Comments by participants at conferences and seminars in St Petersburg, Rome, Milan and Valencia led to significant improvements in the manuscript. This research would not have been possible without the financial support of the European Research Council under the European Union's Seventh Framework Programme (FP7/2007-2013)/ERC grant agreement nº 269868. 


\section{References}

Antonelli, C. (2010) La mossa del cavallo [A knight's tour]. Turin: Rosenberd \& Sellier.

Bank of Italy (2013) L'economia delle regioni italiane [The economy of Italian regions]. Rome: Bank of Italy Annual Report.

Capello, R., Caragliu, A. and Fratesi, U. (2015a) "The Costs of the Economic Crisis: Which Scenarios for the European Regions?", Environment and Planning $C$, forthcoming.

Capello, R., Caragliu, A. and Fratesi, U. (2015b) "Spatial heterogeneity in the costs of the economic crisis in Europe: are cities sources of regional resilience?", Journal of Economic Geography, forthcoming, DOI 10.1093/jeg/lbu053.

Chapple, K., Lester, T.W. (2010) The resilient regional labour market? The US case, Cambridge Journal of Regions, Economy and Society, 3: 85-104

European Commission (2014) Investment for jobs and growth: Promoting development and good governance in EU regions and cities. Sixth report on economic, social and territorial cohesion. Brussels: European Commission.

Fingleton, B., Garretsen, H., Martin, R. (2012). Recessionary shocks and regional employment: evidence on the resilience of UK regions, Journal of Regional Science, 52: $109-133$.

Fingleton, Garretsen and Martin (2014) Shocking aspects of monetary union: the vulnerability of regions in Euroland, Journal of Economic Geography, 15: 907-934

Fitjar, R.D., Rodríguez-Pose, A. (2013) Firm collaboration and modes of innovation in Norway, Research Policy, 42: 128-138.

Fratesi, U., Senn, L. (2009) Regional growth, connections and economic modelling. In U. Fratesi, L. Senn (eds.) Growth and Innovation of Competitive Regions: The Role of Internal and External Connections, pp. 3-27. Berlin: Springer-Verlag.

Gereffi, G. (1999) International trade and industrial upgrading in the apparel commodity chain. Journal of International Economics, 48: 27-70.

Grabher, G. Stark, D. (1997) Organizing diversity: evolutionary theory, network analysis and postsocialism, Regional Studies, 31: 533-544.

Heyes, J. (2011) Flexicurity, employment protection and the jobs crisis, Work, Employment and Society, 25: 642-657.

Hollanders, H., Tarantola, S., Loschky, A. (2009) Regional Innovation Scoreboard (RIS) 2009. 
Martin, R. (2012) Regional economic resilience, hysteresis and recessionary shocks, Journal of Economic Geography, 12:. 1-32.

Martin, R., Sunley, P. (2015) On the notion of regional economic resilience: conceptualization and explanation, Journal of Economic Geography 15: 1-42.

OECD (2011) Regional Outlook: Building resilient regions for stronger economies. Paris: OECD.

Petrakos, G., Rodríguez-Pose, A., Rovolis, A. (2005) Growth, integration, and regional disparities in the European Union, Environment and Planning, A 37: 1837-1855.

Pike, A., Dawley, S., \& Tomaney, J. (2010). Resilience, adaptation and adaptability, Cambridge Journal of Regions, Economy and Society, 3: 59-70.

Rodríguez-Pose, A. (2013) Do institutions matter for regional development? Regional Studies, 47: 1034-1047.

Rodríguez-Pose, A., Fratesi, U. (2007) Regional business cycles and the emergence of sheltered economies in the southern periphery of Europe, Growth and Change, 38: 621648.

Rodríguez-Pose, A., Tselios, V. (2011) Mapping the European regional educational distribution. European Urban and Regional Studies, 18:358-374

The Economist (2012) “America's jobless recovery: The big picture”, Aug 3rd 2012

Trigilia, C. (1992) Sviluppo senza autonomia. Bologna: Il Mulino. 